\title{
¿Estamos preparados para asumir el reto de la Conciliación?
}

Renzo Vigo Carrillo

Con la entrada en vigencia de la Ley de Conciliación Extrajudicial (Ley No 26872) en noviembre de 1997, se declaró de interés nacional la institucionalización y el desarrollo de la conciliación como un mecanismo alternativo al Poder Judicial, señalándose además en su artículo sexto el carácter previo y obligatorio de este mecanismo en los procesos sobre pretensiones determinadas y determinables que versen sobre derechos disponibles de las partes.

Es importante resaltar que entre las ventajas más importantes con las que cuenta la conciliación tenemos:

- En cuanto al tiempo que dura el proceso de conciliación es de uno a treinta días como máximo, dependiendo de la predisposición de las partes a conciliar, así como de la habilidad del conciliador al dirigir al misma.

- En cuanto al costo del proceso de conciliación, éste será mucho menor si lo comparamos con el costo que demandaría un proceso judicial, dado que el pago será uno solo (al comienzo del proceso de conciliación).

- En cuanto al acuerdo mismo. Serán las mimas partes las que busquen llegar a dicho acuerdo, el conciliador sólo podrá sugerir alguna alternativa de solución, que quedará a criterio de las partes aceptarla o no.

- En cuanto a los efectos del Acta de Conciliación, podemos señalar que ésta tendrá valor de Título de Ejecución (sentencia de última instancia), con lo cual, si una de las partes incumple el acuerdo al que han llegado vía el Acta de Conciliación, la otra parte podrá 
pedir al juez, ya no que conozca el proceso, sino que exija el cumplimiento del mismo.

Si bien, la entrada en vigencia de la obligatoriedad de la Conciliaciónn, como mecanismo previo a todo proceso judicial, comenzaba a regir en enero del año 2000 , según lo establecía la tercera disposición, transitoria y final de la Ley 26872 se prorrogó dicha obligatoriedad hasta el 14 de enero del 2001.

¿Qué razones fueron las que llevaron a retardar la entrada en vigencia de la obligatoriedad de la Ley? ¿Por qué dilatar más la institucionalización de un mecanismo tan efectivo, rápido y económico, en el cual ya muchas personas se encontraban inmersas y con muchas expectativas (económica, social, etc.)?

En el Fórum Internacional Retos y Posibilidades, llevado a cabo a fines del año pasado en nuestra casa de estudios, la Secretaria Técnica de Conciliación del Ministerio de Justicia, Dra. María Luisa Valdez Bortesi, trató de explicar al público asistente los motivos que habrían llevado a dicho Ministerio, como ente rector y encargado de la implementación de la conciliación en nuestro país, el proponer al Ejecutivo la prórroga de la obligatoriedad de ésta como medida urgente y necesaria.

Las razones fueron de cierta manera comprensibles pero un tanto paradójicas y preocupantes, por lo que a partir de esa fecha una inquietud es la que rodea la mente de todos aquellos que apostamos por la conciliación:

\section{1. ¿Estamos realmente preparados para el reto?}

Este es el dilema que da título a este artículo y es la interrogante que vamos a intentar responder a lo largo de estas pocas líneas.

Empezaremos por analizar los argumentos que habría llevado al Ministerio de Justicia a proponer dicha postergación:

$1{ }^{\circ}$ Número de salas de audiencias de conciliación según la carga procesal: «El Ministerio considera que para la Conciliación Extrajudicial cumpla sus fines debe existir una adecuada proporción entre centros de conciliación y carga procesal. Si los centros no pueden atender 
las solicitudes de conciliación dentro de los plazos fijados por la ley, se crearían un cuello de botella, ya que las personas no podrían conciliar y tampoco podrían acceder la Poder Judicial».

20 Difusión de la conciliación: «La segunda razón es que las personas deben conocer la institución de la conciliación, los principios en los cuales se basan, sus ventajas, las facultades del conciliador, el valor del acuerdo, y otras características de esta institución que les lleve a confiar en ella».

\section{Número de salas de Conciliación, según la Carga Procesal}

Al respecto la doctora Valdez, señaló que en la actualidad no se cuenta con el número de salas de audiencias de conciliación suficientes para poder atender la carga procesal que actualmente enfrenta el Poder Judicial. En este sentido, es importante resaltar los datos estadísticos proporcionados por la Gerencia Central de la Reforma del poder Judicial, en donde se ha podido establecer que de regir la obligatoriedad en enero del año 2000, la carga que deberán de soportar los centros de conciliación es aproximadamente de 3970 demandas civiles mensuales, sin tener en cuenta las materias laborales y de familia.

A la fecha de la exposición existían en Lima 12 centros de conciliación privados autorizados por el Ministerio de justicia y en la mayoría de los casos con sólo una sala de audiencia, y calculando que por sala se podrían realizar 3 audiencias por día, siendo necesario para que los usuarios puedan cumplir con el requisito de la obligatoriedad de la conciliación previa a un proceso judicial, se cuente por lo menos con 66 salas de audiencias en promedio, para soportar el total de la demanda proyectada. Si bien los juzgados de paz y las Demunas también están autorizados para realizar conciliaciones extrajudiciales en esos momentos, ello no era suficiente para poder atender la demanda antes mencionada. Al respecto, es importante llamar la atención sobre la forma tan deficiente como se están dando las conciliaciones extrajudiciales en la mayoría de las Demunas, que en vez de crear un clima de confianza hacia dicha institución, la limita, por lo que dicha situación trae consigo otra interrogante que si bien en esta oportunidad no la desarrollaremos la queremos dejar planteada: ¿están preparadas las Demunas y los juzgados de paz para poder llevar adelante la conciliación con la eficacia requerida? 
En conclusión, estamos de acuerdo con el Ministerio de Justicia, en cuanto a la necesidad de suspender la obligatoriedad de la conciliación hasta que se logre alcanzar este número mínimo de salas, por que de no ser así la obligatoriedad podría volverse en un obstáculo para acceder a los órganos jurisdiccionales.

Lo que sí me parece importante resaltar es que en la actualidad existen 23 centros de conciliación en Lima y 41 a nivel nacional, y 20 solicitudes para la autorización de centros de conciliación a nivel nacional, con lo cual se espera que a fin de año se sobrepase la cifra mínima esperada para atender la carga procesal existente. Lo que habrá que definirse es si la obligatoriedad de la conciliación es sólo para Lima o también para otras ciudades del país. Consideramos que esto dependerá del número de centros de conciliación que se creen en las distintas ciudades del país; quizás lo más recomendable será que se inicie la vigencia de la obligatoriedad en la ciudad de Lima y progresivamente ir implementándola en las demás ciudades del país.

\section{Difusión de la Conciliación}

Nosotros consideramos que es de vital importancia, para que la conciliación pueda llevarse a cabo con éxito, que se dé una campaña de amplia difusión, que llegue a todos los rincones del país dado que en principio la Ley de Conciliación será obligatoria a nivel nacional.

Es importante que las personas tomen conciencia de las principales ventajas que trae consigo la conciliación, las facultades del conciliador, el valor del acuerdo, y demás características de esta institución que les lleve a confiar y apostar por ella.

Si bien la Dra. María Luisa Valdez tiene razón en mencionar la poca difusión que se le ha hecho a la conciliación, creemos también que esa es una de las más importantes funciones que deberían tener ellos a su cargo, como se hizo en Colombia, uno de los pocos países a nivel sudamericano en que tuvo cierto éxito.

Tenemos conocimiento que el Ministerio de Justicia, en este sentido, ha tomado cartas en el asunto (durante 1999 realizó 56 charlas de difusión a nivel nacional), pero aún así consideramos que la campaña de difusión tendría que ser mucho más ambiciosa si se quiere obtener el éxito esperado, y entendemos que ello dependerá del presupuesto 
asignado a dicho Ministerio, por lo que esperamos que el Estado tome en cuenta dicho aspecto.

Ahora bien, creemos también que esta función no debería ser exclusivamente del Ministerio de Justicia sino también de los centros de conciliación autorizados por éste, dado que el interés por el éxito de la Conciliación no sólo es del Ministerio sino de cada una de las instituciones que han invertido para poder formar su centro de conciliación y para ello consideramos pertinente que a la Ley de Conciliación vigente se le debería añadir en su Capítulo IV (De los Centros de Conciliación) artículo $24^{\circ}$ la función de difusión como objeto de dichas entidades.

Asimismo, sería importante añadir como requisito para la aprobación de un centro de conciliación (artículo $27^{\circ}$ de la Ley de Conciliación) que en el reglamento de dicho centro se comprometa con dictar como mínimo seis charlas de difusión anualmente, dando con ello al Ministerio de Justicia una herramienta importante para poder añadir a su labor de supervisión, comprobando que dichos centros cumplan con el dictado de dichas charlas (dicha función se añadiría en el artículo $48^{\circ}$ del Reglamento de la ley de conciliación vigente), dado que si bien en el Reglamento Tipo de los Centros de Conciliación, aprobado por Resolución Ministerial No 081-98-JUS, se establece en una de las funciones del Director (Título II, Capítulo II, artículo $3^{\circ}$ inciso g) «el de promover y coordinar con otros Centros, Universidades o similares, y con el Ministerio de Justicia, actividades de tipo académico relacionadas con la difusión de la Conciliación y la capacitación de los conciliadores", ello al parecer no ha tenido la fuerza suficiente para llevar adelante una campaña agresiva de difusión, siendo por ello importante tomar en cuenta lo antes mencionado.

\section{Aprobación y supervisión de los cursos de formación y capacita- ción de conciliadores}

La doctora Valdez, en su ponencia, resaltó la función del Ministerio de Justicia de aprobar y supervisar los cursos de formación y capacitación de conciliadores, en el sentido de que «los conciliadores deben estar bien capacitados, ya que de la seriedad, calidad y ética de su trabajo dependerá en gran medida el éxito de la Conciliación del país». 
Por esta razón, el Ministerio de Justicia ha creído conveniente aumentar las exigencias de los cursos de capacitación en cuanto a horas lectivas, forma de evaluación, perfil de conciliadores, número máximo de participantes, entre otros, y supervisar que esto se cumpla». Al respecto, si bien estamos de acuerdo con la política asumida por el Ministerio de Justicia quisiéramos mencionar dos puntos a tomar en cuenta:

$1^{\circ} \mathrm{Si}$ bien los requisitos adicionales exigidos por el Ministerio para autorizar los cursos de formación y capacitación nos parecen necesarios, en la medida que contribuye a que los conciliadores puedan obtener una mejor y mayor preparación, consideramos también que dichos requisitos deberían dar lugar a una modificación de la Ley, dado que en algunos casos, centros autorizados para dictar cursos de formación y capacitación de conciliadores, utilizando influencias políticas, logran que el ministerio apruebe estos cursos sin cumplir con los requisitos adicionales antes mencionados, aduciendo que «dichos requisitos no están normados, por lo que el Ministerio no puede obligar a cumplirlos» demostrando con ello que lo único que les interesa son los beneficios económicos que les puede otorgar la conciliación a través del dictado de dichos cursos, y muy poco el hecho de que tengamos conciliadores debidamente capacitados $y$ preparados para dicha función, con lo cual, al final dichos requisitos se les exigen sólo a algunos centros, lo cual nos parece desde todo punto de vista injusto.

$2^{\circ}$ Consideramos necesario que para que la formación y capacitación de conciliadores sean eficientes, es necesario que la supervisión a la cual hizo referencia la doctora Valdez se dé en forma rigurosa y no en la forma como en la actualidad se está dando. Existen muchos casos de centros de conciliación que "obsequian" la aprobación del curso y que frente a estos hechos, hasta ahora el Ministerio no toma cartas en el asunto, dedicándose solamente a acreditar a dichas personas. Creemos necesario que el Ministerio debería tener una participación más activa en la supervisión de las audiencias de simulación, dado que es allí en donde el postulante a conciliador demuestra cuánto puede haber interiorizado lo aprendido y en donde puede ver si realmente dicho postulante cuenta con lo que se conoce criollamente con «la pasta para ser conciliador». 
Por los argumentos antes mencionados, consideramos que para que la conciliación tenga éxito, para que nuestra población crea en ella, debemos tener buenos conciliadores que transmitan de la mejor manera la cultura de paz y por ende la conciliación, y ello dependerá no sólo del Ministerio de Justicia, sino también de los mismos centros de formación y capacitación, en la medida que cumplan de forma honesta la labor delegada.

\section{Conclusiones}

Luego de haber analizado las razones que llevaron a postergar la entrada en vigencia de la obligatoriedad de la conciliación en el Perú, consideramos que por ahora no estamos preparados para poder llevarla adelante, dado que si bien el problema del escaso número de centros de conciliación que pueda atender la alta carga procesal por la que hoy atravesamos se puede superar, según el análisis antes realizado, creemos que de la forma como se está llevando a cabo la campaña de difusión de la conciliación, es poco probable que se obtenga éxito. Sin embargo, creemos que aún estamos a tiempo para cambiar el rumbo, en la medida que:

- Se empiece a dar de una manera más intensa una campaña de difusión, que si bien tenga como centro de difusión al Ministerio de Justicia, se de también a través de los centros de conciliación, logrando con ello, que llegue a la mayoría de la población todos los beneficios que en sí trae consigo la conciliación. Sería fundamental que como producto de dicha difusión, la gente empiece a conocer y creer en la conciliación, conozca los principios en los cuales se basan, despierte en ellos el interés por aprovechar las distintas ventajas que trae consigo esta institución, impidiendo que se convierta en un mero mecanismo de procedibilidad, como se ha dado en otros países.

$\mathrm{Al}$ respecto, quisiera tomar como ejemplo lo ocurrido con Argentina a raíz de la vigencia de la Ley de Mediación (que viene a ser lo que nosotros conocemos por conciliación), en donde si bien la legislación que regula la mediación presenta ciertas particularidades, como que para ser mediador es necesario ser abogado, también 
muestra semejanzas con nuestra Ley de Conciliación siendo una de ellas el hecho de que desde un comienzo la conciliación se reguló como un requisito previo de procedibilidad, lo cual, debido a la poca campaña de difusión que se realizó en dicho país, ocasionó que la gente recurriera a los centros de conciliación, no tanto por la convicción que tenía en dicho proceso, sino por la obligatoriedad antes mencionada, habiendo que tomar en cuenta además que la inasistencia de las partes a las audiencias de conciliación es sancionada con una multa.

Como mencioné anteriormente, si bien en esta sentido el Ministerio de Justicia ha tomado cartas en el asunto (aunque creemos que su acción debiera de ser más agresiva), consideramos también que la campaña de difusión no sólo es competencia del Ministerio sino también de los centros de conciliación y de los centros de formación y capacitación de conciliadores. Es tiempo de que todos los que verdaderamente creemos en la conciliación nos unamos y saquemos adelante esta institución, logrando con ello no sólo que las personas confíen en ella, sino también el de crear a través de la conciliación, una cultura de paz que permita desarrollarnos como país.

- Como consecuencia de la campaña de difusión antes mencionada, se podrá conseguir también que más personas quieran ser conciliadores y, a la vez, quieran formar su propio centro de conciliación, con lo cual tendremos mayor posibilidad de atender la gran carga procesal que ahora enfrentamos.

- Por último, consideramos de vital importancia, que el Ministerio de Justicia supervise de una manera más rigurosa la capacitación de los conciliadores, dado que de ello dependerá la confianza de la población en la conciliación. 